OPEN ACCESS

Edited by:

Markus H Hoffmann,

University of Lübeck, Germany

Reviewed by:

Inken Schmudde,

University of Lübeck, Germany

Umut Can Kucuksezer,

Istanbul University, Turkey

*Correspondence:

Wenhua Zhu

zhuwenhua@xitu.edu.cn

Liesu Meng

mengliesu@xjtu.edu.cn

${ }^{\dagger}$ These authors share senior authorship

Specialty section: This article was submitted to Inflammation,

a section of the journal

Frontiers in Immunology

Received: 27 September 2021 Accepted: 29 November 2021

Published: 14 December 2021

Citation:

Li M, Zhang W, Zhang J, LiX, Zhang F, Zhu W, Meng L, Holmdahl $R$ and Lu S (2021) Ncf1 Governs Immune Niches in the Lung to Mediate

Pulmonary Inflammation in Mice.

Front. Immunol. 12:783944.

doi: 10.3389/fimmu.2021.783944

\section{Ncf1 Governs Immune Niches in the Lung to Mediate Pulmonary Inflammation in Mice}

\author{
Mengyao $\mathrm{Li}^{1}$, Wentao Zhang ${ }^{1}$, Jing Zhang ${ }^{1}$, Xiaowei $\mathrm{Li}^{2}$, Fujun Zhang ${ }^{1,3}$, Wenhua Zhu ${ }^{1,3^{*}}$, \\ Liesu Meng ${ }^{1,3 *}$, Rikard Holmdahl ${ }^{2,4 t}$ and Shemin $\mathrm{Lu}^{1,3 \dagger}$ \\ ${ }^{1}$ Department of Biochemistry and Molecular Biology, Institute of Molecular and Translational Medicine, School of Basic \\ Medical Sciences, Xi'an Jiaotong University Health Science Center, Xi'an, China, ${ }^{2}$ National Joint Engineering Research \\ Center of Biodiagnostics and Biotherapy, Second Affiliated Hospital, Xi'an Jiaotong University, Xi'an, China, ${ }^{3}$ Key Laboratory \\ of Environment and Genes Related to Diseases (X'ian Jiaotong University), Ministry of Education, Xi'an, China, \\ ${ }^{4}$ Section for Medical Inflammation Research, Department of Medical Biochemistry and Biophysics, Karolinska Institute, \\ Stockholm, Sweden
}

Neutrophil cytosolic factor 1 (Ncf1) is a major genetic factor associated with autoimmune diseases and has been identified as a key player in autoimmune mediated inflammation. We addressed the role of Ncf1 in an antigen-induced pulmonary inflammation model, and found that the $\mathrm{Ncf}^{\mathrm{m}{ }^{1 j}}$ mutation, causing a deficient reactive oxygen species response, alleviated disease. The $\mathrm{Ncf1}^{\mathrm{m1j}}$ mutation was associated with a reduced inflammatory cell infiltration in airways, but had limited effect on mucus secretion, antibody production and lung fibrosis. The disease remission in the Ncf1 mutated mice was reversed when functional Ncf1 was transgenically expressed in alveolar macrophages, suggesting that the cellular inflammation was depended on functional Ncf1 in alveolar macrophages. By determining cytokine and chemokine profiles in lung and serum, we found that Ncf1 deficiency allowed an increased expression of Th1 cytokines, including TNF- $\alpha$, IFN- $\gamma$ and IL-12. Since also epithelial cytokines were found to be regulated by Ncf1, we tested the effect of Ncf1 in IL-33 and IL-25 induced lung inflammation models. Mice with the Ncf1 ${ }^{\mathrm{m} 1 j}$ mutation showed less sensitivity to IL-33, but not IL-25, induced lung inflammation, in a macrophage independent manner. The mice with deficient Ncf1 showed a reduced eosinophil infiltration and group 2 innate lymphoid cell (ILC2) activation. The production of IFN- $\gamma$ in CD4 ${ }^{+} \mathrm{T}$ cells was increased, whereas IL-5 and IL-13 in ILC2 were decreased. Importantly, anti-IFN- $\gamma$ antibody treatment of Ncf1 deficient mice increased eosinophil infiltration and rescued ILC2 activation in the lung. We conclude that Ncf1 deficiency enhances Th1 response, deactivates ILC2, and protects against pulmonitis.

Keywords: asthma, macrophages, Th1 response, ILC2, Ncf1 


\section{INTRODUCTION}

Allergic asthma is characterized by airway inflammation, smooth muscle contraction, epithelial cell exfoliation, over secretion of mucus and bronchial hyperresponsiveness, and is a common complex disease associated with a combination of genetic and environmental factors (1). It is known that environmental allergens, viruses, bacteria and smoking can irritate the airway epithelium, activating exaggerated innate and adaptive immune responses, and triggering the development of asthma (2). The enhanced Thelper (Th) 2 immune response mediates the allergic inflammation, which is characterized by the production of interleukin (IL)-4, IL-5 and IL-13, and further results in eosinophil infiltration, mucus secretion, and airway remodelling (3). Interestingly, activation of group 2 innate lymphoid cells (ILC2) seems to precede a Th2 response. The ILC2 are activated by the airway epithelial-derived cytokines including IL-25, IL-33 and thymic stromal lymphopoietin (TSLP), leading to the production of the Th2 cytokines IL-5 and IL-13, and also activation of eosinophils $(2,4,5)$. In addition, Th17 cytokines could synergize with Th2 cytokines in the pathogenesis of asthma $(6,7)$. Although Th2 mediated immunity seems to be involved in asthmatic diseases, it is also important in the physiology and its precise role in the pathogenicity is more difficult to understand. For this it would be helpful to unravel the role of the disease-causing genes and environmental factors.

Many chromosomal loci have been reported to be associated with asthma susceptibility, but none has so far been conclusively identified and validated functionally (8). To position genetic polymorphisms associated with complex diseases is a challenging task but more recently several single nucleotide polymorphisms (SNPs) associated with chronic inflammation have been identified in animal models (9-11). The first finding was the positionally cloning of the neutrophil cytosolic factor 1 ( Ncf1) gene to be associated with arthritis in a rat model (12). Subsequently, it was confirmed that Ncf1 is also associated with a variety of chronic inflammatory diseases in both animals but importantly also in humans, such as rheumatoid arthritis and systemic lupus erythematosus (SLE) $(13,14)$. The Ncf1 protein (earlier denoted p47phox) is a critical component of the NADPH oxidase (NOX) 2 complex, mediating the induction of reactive oxygen species (ROS) by inflammatory stimuli. Only a few studies have investigated the role of $N c f 1$ in lung diseases. We have found that $N c f 1$ mutant mice lacking ROS are less susceptible to transplanted lung tumors (15). A longer progression free survival (PFS) of patients with primary nonsmall cell lung cancer (NSCLC) was associated with higher levels of $N c f 1$, and low levels of $N c f 1$ may be used as a biomarker for predicting response of patients with primary NSCLC to anti-PD1 therapy (16). A fully functional $N c f 1$ gene was found to be required for development of isocyanate-induced lung inflammation (17), and for development of SARS and influenza virus induced lung hyperinflammation in the mouse (18). However, the role of $N c f 1$ in the pulmonary inflammatory diseases like asthma remains unknown.
In the present study, we have investigated the immune regulatory role of Ncf1 in asthma, and found that mice with the $N c f 1^{m l j}$ mutation, with a dysfunctional ROS response, were protected from ovalbumin (OVA)-induced lung inflammation in an alveolar macrophage dependent manner, with reduced inflammatory cell infiltration in airways and an increased Th1 cytokine expression in the lungs. Interestingly, the Ncf1 deficiency was associated with a reduced ILC2 activation, which alleviated lung inflammation caused by IL-33. Our study reveals a new candidate involved in skewing the Th1/Th2 balance, which provides a new insight in understanding the pathogenesis of asthma, and also a potential target for the disease treatment.

\section{MATERIALS AND METHODS}

\section{Mice}

B10Q mice (C57/Bl10.Q/rhd) were originally from Jan Klein (Tübingen University, Tübingen, Germany) (19), and maintained in the medical inflammation research lab led by Rikard Holmdahl (rhd). B10Q.Ncf1* mice indicate B10Q mice with a mutation in the Ncf1 gene (m1j), in which the NOX2 complex function is impaired but not deleted $(19,20)$. B10Q.Ncf1 $1^{*}$.MN strain transgenically expresses $N c f 1$ under the control of the CD68 promotor in a B10Q mouse having the $N c f 1^{\mathrm{mlj}}$ mutation, thus expressing $N c f 1$ in macrophages only. The above mice were maintained in SPF animal feeding equipment of the Experimental Animal Center of Xi'an Jiaotong University Health Science Center. In this study, female mice aged 8 to 12 weeks were used. All animal experiments followed ARRIVE guidelines and were approved by the Institutional Animal Ethics Committee of Xi'an Jiaotong University.

\section{Antigen-induced Pulmonary Inflammation (AIPI)}

Female B10Q, B10Q.Ncf1 ${ }^{\star}$ and B10Q.Ncf1*.MN mice were used to induce AIPI model essentially following previously described protocols (10). A colloid emulsion was prepared by mixing 0.1 $\mathrm{mg} / \mathrm{ml}$ OVA (Sigma) and Imject ${ }^{\mathrm{TM}}$ Alum (Pierce, Thermo Fisher Scientific) in equal volume. The mice were sensitized by intraperitoneal injection of the OVA emulsion $(200 \mu \mathrm{l}$ per mouse) at days 0 and 7 . From day 14, the mice were challenged with $1 \%$ OVA aerosol for $30 \mathrm{~min}$ per day for 7 consecutive days. On day 21, blood, bronchoalveolar lavage fluid (BALF) and lung tissues were collected.

\section{Histological Staining}

Lung tissues from the lower left lobe were fixed with $4 \%$ paraformaldehyde (SinoPharm, China), embedded in paraffin (Hualing, Shanghai, China), sectioned, and then stained with hematoxylin and eosin (H\&E, Solarbio, China), periodic acid Schiff (PAS, Solarbio, China) and Masson (Solarbio, China) (10). Peritracheal inflammatory cell infiltration was scored by an investigator with no knowledge of the sample identities, 
according to the number of layers of infiltrating cells, as previously described (10). Score 0: no peritracheal infiltrating cells. Score 1: sporadic infiltrating cells around the tube, less than one layer; Score 2: peritubule infiltrating cells reached 1-2 layers; Score 3: peritubule infiltrating cells up to 2-3 layers; Score 4: peritubule infiltrating cells with 3-5 layers; Score 5: more than 5 layers with peritubule infiltrating cells. Both the portion of goblet cell staining of airway mucus and the degree of airway fibrosis were scanned using Image Pro Plus software and normalized with relative airway area.

\section{Enzyme Linked Immunosorbent Assay (ELISA)}

To quantify the levels of OVA-specific IgE and OVA-specific IgG1 in serum, a 96-well plate was coated with OVA $(5 \mu \mathrm{g} / \mathrm{ml}$, Sigma) overnight and blocked using $1 \%$ bovine serum albumin (BSA, Amresco). Diluted sera were added for 2 hour incubation, followed by rat anti-mouse IgE-biotin (clone No. 23G3, SouthernBiotech) or rat anti-mouse IgG1-biotin (clone No. LO-MG1-2, Bio-Rad) antibodies, and developed with streptavidin-horseradish peroxidase (HRP, R\&D systems, Biotechne). The reaction was visualized by using the substrate ABTS (Roche) and read at $405 \mathrm{~nm}$ using a microplate reader (Thermo Electron Corporation) (10).

\section{Luminex Assay}

Selected cytokines and chemokines including chemokine (C-X-C motif) ligand (CXCL) 1 (range: 9.9-7220 pg/ml), tumor necrosis factor (TNF)- $\alpha$ (0.81-590 pg/ml), IL-12p70 (14.95-10900 pg/ml), IL-1 $\beta$ (76.74-55940 pg/ml), vascular endothelial growth factor (VEGF, 1.48-1080 pg/ml), IL-4 (20.44-14900 pg/ml), IL-5 (1.621180 pg/ml), IL-6 (8.41-6130 pg/ml), IL-10 (4.6-3350 pg/ml), IL-13 (16.69-12170 pg/ml), IL-17 (14.12-10290 pg/ml), interferon (IFN)$\gamma(4.39-3200 \mathrm{pg} / \mathrm{ml})$, IL-33 (27.59-20110 pg/ml), IL-25 (46.82$34130 \mathrm{pg} / \mathrm{ml}$ ), C-C motif chemokine ligand (CCL) 11 (4.24-3090 $\mathrm{pg} / \mathrm{ml}$ ) were quantified in serum samples of mice using a 15-plex Luminex panel (LXSAMSM-15, R\&D Systems). The sample was diluted twice and the plate was detected by Luminex X-200.

\section{mRNA Quantification}

Total RNA was extracted from lung tissue of mice using TRIzol reagent (Invitrogen) and cDNA was synthesized using the first strand cDNA synthesis Kit (Fermentas). Agilent Stratagene

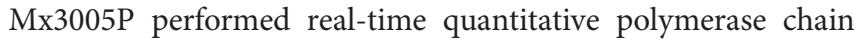
reaction (RT-qPCR) with FastStart Universal SYBR Green Master (Roche) to assess cytokine expression. Mouse $\beta$-actin gene was used as a housekeeping gene. The primers used in this experiment are listed in the Supplementary Table 1.

\section{Epithelial Cytokine Induced Lung Inflammation}

On day 0 and day 1 , female mice with three genotypes were treated with IL-33 (0.5 $\mu \mathrm{g} /$ mouse, SinoBiological) $(21)$ or IL-25 (1.5 $\mu \mathrm{g} /$ mouse, SinoBiological) (22) intranasally, respectively. On the $3 \mathrm{rd}$ day, mice were sacrificed and the whole lungs were taken and digested for flow cytometry assay.

\section{Flow Cytometry}

Lung tissues were minced and digested by using collagenase type I ( $1 \mathrm{mg} / \mathrm{ml}$, Sigma) and DNase $(25 \mu \mathrm{g} / \mathrm{ml}$, Sigma) for $1 \mathrm{~h}$. Cells from lung tissue or BALF were first stained with LIVE/DEAD Fixable Violet stain kit (Thermo Fisher), and labeled with the following monoclonal antibodies for the membrane antigen staining: antiCD45.2-BV785, anti-CD11b-APC (allophycocyanin), anti-CD11cAPC-Cy7, anti-F4/80-FITC, anti-Ly6G-Pacific blue, anti-Siglec FPerCP (peridinin chlorophyll protein)-Cy5.5, anti- $\gamma \delta \mathrm{T}$ cell receptor (TCR)-PE (phycoerythrin), anti-TCR $\beta$-Alexa Fluor 700, anti-B220-PE-Cy7, anti-CD4-PE-Cy5, mouse lineage antibody cocktail-PerCP-Cy5.5, anti-ST2-BV421 and anti-CD68-Pacific blue. For cytokine staining, cells were pre-treated with phorbol 12-myristate 13-acetate (PMA, $100 \mathrm{ng} / \mathrm{ml}$, Sigma), ionomycin (1 $\mu \mathrm{g} / \mathrm{ml}$, Sigma $)$ and brefeldin A (10 $\mu \mathrm{g} / \mathrm{ml}$, Selleck) for $3 \mathrm{~h}$, fixed and permeated by using BD Cytofix/Cytoperm after membrane staining, and labeled with the following monoclonal antibodies for intracellular staining: anti-IL-5-PE, anti-IL-13-PE-Cy7, antiIFN- $\gamma$-Pacific blue. Mouse lineage antibody cocktail could react with cells from the major hematopoietic lineages, such as T cells, B cells, monocytes/macrophages, NK cells, erythrocytes, and granulocytes, which includes clone 145-2C11 (recognizes CD3e), M1/70 (recognizes CD11b), RA3-6B2 (recognizes B220), TER-119 (recognizes Ly-76), and RB6-8C5 (recognizes Ly-6G and Ly-6C). The detailed antibody information is shown in Supplementary Table 2. Samples were analyzed using an Agilent NovoCyte 3005 flow cytometer. Immune cell gating strategy and the fluorescenceminus-one (FMO) staining controls are shown in Supplementary Figures 1, 2.

\section{Anti-IFN- $\gamma$ Antibody Intervention}

On day 0 , IFN- $\gamma$ antibody or isotype IgG (200 $\mu$ g per mouse, Bio $\mathrm{X}$ Cell) was injected intravenously to B10Q.Ncf1* mice. Then on day 0 and day 1 , mice were treated with IL-33 (0.5 $\mu$ g per mouse, SinoBiological) intranasally. On the third day, the whole lung was isolated, and flow cytometry was performed after digestion.

\section{Statistical Analysis}

Graphpad Prism software was used for statistical analysis and graph construction. The quantitative data are expressed by mean \pm SEM. The differences were statistically analyzed using one-way ANOVA with post-hoc comparison (Fisher's) test among three experimental groups or the student's $t$ test between two experimental groups. A $P$ value of less than 0.05 is considered significant.

\section{RESULTS}

\section{Residential Macrophage-Specific Ncf1 Contributes to Inflammatory Cell Infiltration to Mediate AIPI in Mice}

To determine the role of $N c f 1$ in lung inflammation, B10Q.Ncf1* mice were compared with B10Q littermates. We did not find any significant difference in lung tissue structure, or change in the composition of immune cell populations in naïve mice 
(Figure S3A-C). Then we investigated the AIPI model using OVA as an antigen, to induce symptoms resembling asthma (Figure 1A). We found that the total number of immune cells in the BALF were lower in B10Q.Ncf1* mice (Figure 1B). Particularly, the number and the cell proportion of eosinophils were both reduced in B10Q.Ncf1* mice compared with the wildtype littermates (Figures 1B, C). Thus, a functional Ncf1 was important to allow an allergic inflammation in the lung.

$N c f 1$ is highly expressed in phagocytic cells, including macrophages and neutrophils (23). We next addressed the role of $N c f 1$ in macrophages, due to their central regulatory role in both innate and adaptive immunity. A transgenic mouse strain, B10Q.Ncf1*.MN (MN) was used, which transgenically expresses physiologic levels of functional Ncf1 with the help of a CD68 promotor (24). We confirmed CD68 expression in BALF cells by flow cytometry and found that it was highly expressed on residential alveolar macrophages in lung, but not on infiltrating interstitial macrophages, neutrophils, eosinophils or dendritic cells (DC), suggesting that alveolar macrophages of B10Q.Ncf1*.MN mice had functional $N c f 1$ (Figure 1D).

We then induced AIPI in the three strains, wild-type, $N c f 1^{\star}$ and MN mice. Histological analyses were performed on lung tissues showing the extent of inflammatory infiltration around the airway, mucus secretion of airway epithelia and airway fibrosis (Figure 2A). H\&E staining showed that the degree of peri-airway inflammatory infiltration in Ncf1 deficient mice was significantly lower than that in wild-type mice, and $\mathrm{MN}$ tended to compensate for this difference (Figure 2B). However, Ncf1 deficiency had no significant effect on the production of airway mucus and the airway fibrosis, although a trend in the PAS staining could be observed (Figures 2C, D). At the same time, we found that $N c f 1$ deficient mice showed no difference in the
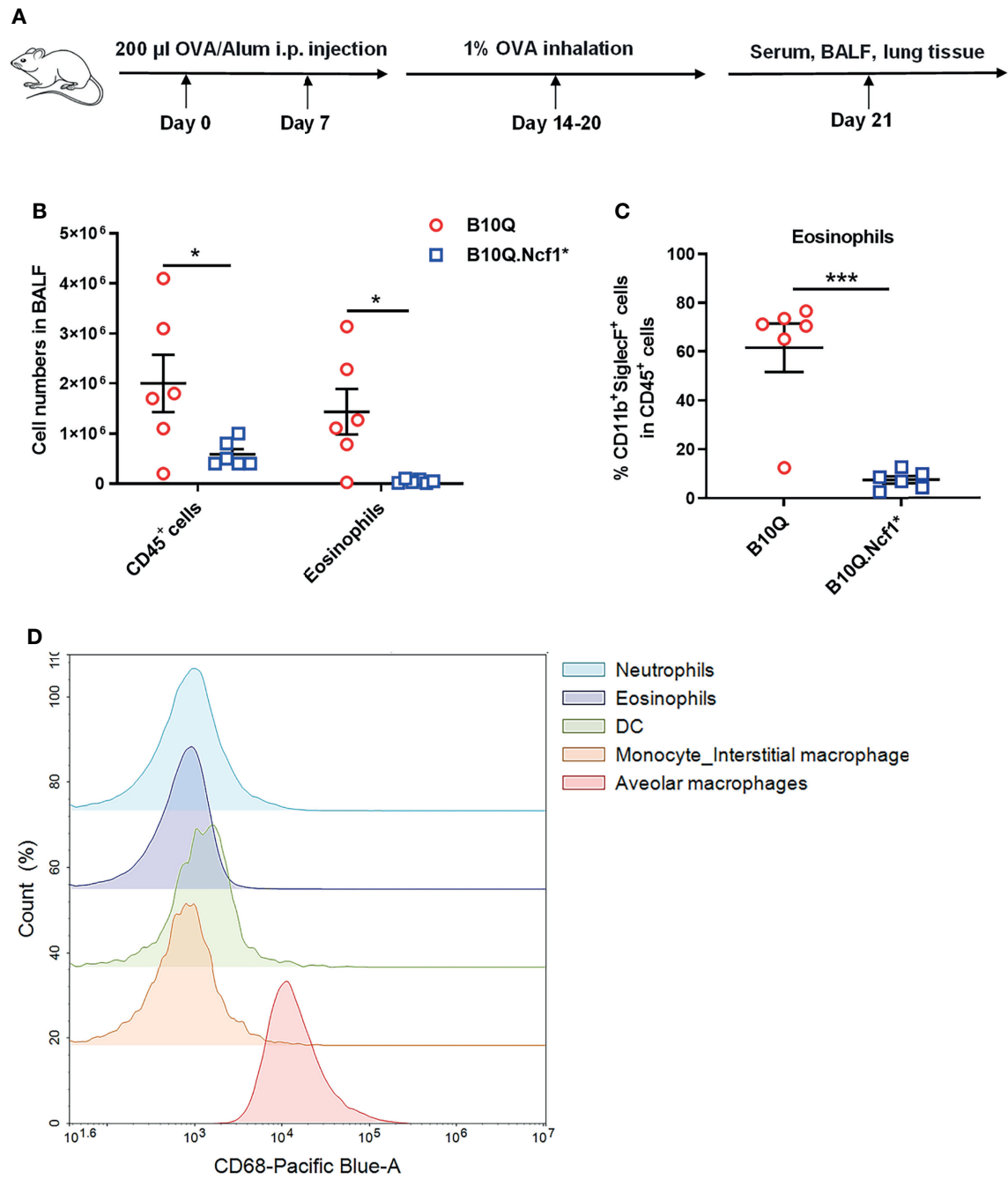

FIGURE 1 | Systemic deficiency of Ncf1 alleviates lung inflammation in mice. (A) A scheme of antigen-induced pulmonary inflammation model in mice. B10Q and B10Q.Ncf1* mice were induced to develop AIPI ( $\mathrm{n}=6$ per group). (B, C) The number of CD45 ${ }^{+}$cells and eosinophils in BALF were analyzed by flow cytometry, and the proportion of eosinophils in CD45 ${ }^{+}$cells was determined. (D) The CD68 ${ }^{+}$cells in BALF were also identified by flow cytometry. All values are expressed as means \pm SEM. ${ }^{\star} P<0.05$ and ${ }^{\star \star \star} P<0.001$, using student's $t$ test. 

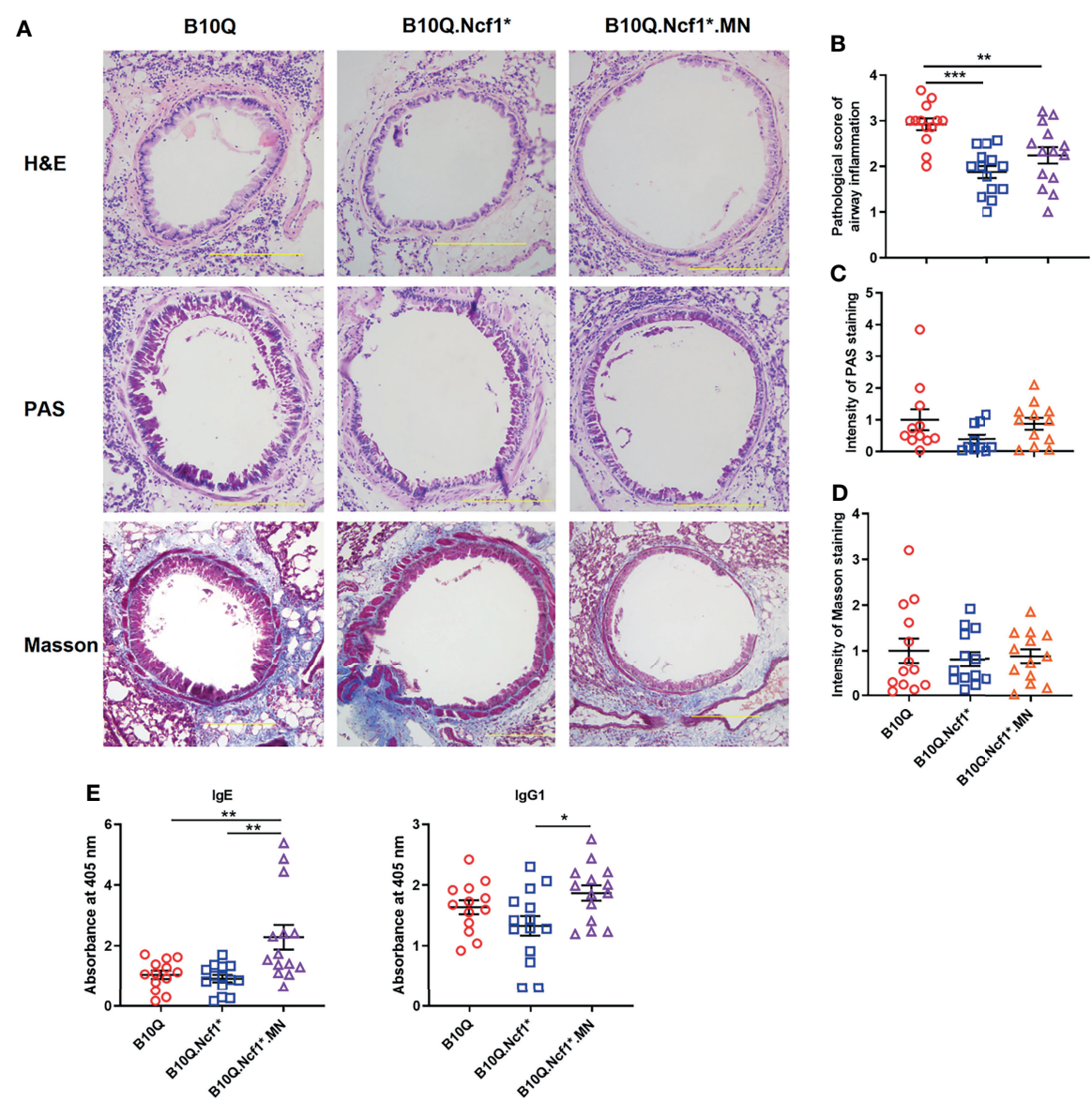

FIGURE 2 | Residential macrophage specific Ncf1 contributes to the development of AIPI in mice. (A) Lung tissues of AIPI model induced in B10Q, B10Q.Ncf1* and B10Q.Ncf1*.MN mice were stained by H\&E, PAS and Masson staining ( $n=10-14$ per group). Bar $=200 \mu \mathrm{m}$. (B) Assess the degree of inflammatory infiltration around the airways. (C, D) Assess the airway mucus generation and the degree of airway fibrosis with Image Pro Plus software. (E) The concentrations of OVA-specific IgE and IgG1 in serum were detected by ELISA, and the relative values are shown as the absorbance at $405 \mathrm{~nm}(\mathrm{n}=13-14$ per group). All values are expressed as means \pm SEM. ${ }^{\star} P<0.05,{ }^{\star \star} P<0.01$ and ${ }^{\star \star \star} P<0.001$, using one-way ANOVA with post-hoc comparison (Fisher's) test.

production of OVA-specific IgE and IgG1 compared with wildtype, although MN mice showed higher antibody levels (Figure 2E).

The inflammatory cell profiles of cells infiltrating in lungs were studied by flow cytometry. The results of staining of BALF cells are visually represented via a cluster heat map, which revealed a clustering of the inflammatory profiles of $N c f 1$ deficient mice versus the wild-type mice, and with the MN mice in between (Figure 3A). When Ncf1 was deficient, the total number of cells and various inflammatory cells in BALF were significantly decreased compared with wild-type (Figure 3B), and the proportion of eosinophils was also decreased (Figure 3C). Clearly, the replenishment of Ncf1 in alveolar macrophages could compensate for the above differences to a certain extent (Figures 3B, C). In addition, the population of immune cells in lung tissue was also analyzed, and the result of lung tissue was very similar to that of BALF, with reduced numbers of total immune cells and eosinophils in Ncf1 deficient mice (Figures 3D, E). Taken together, the results suggest that expression of a functional Ncf1 allows the development of lung inflammation, which is mainly depended on Ncf1 expressing alveolar macrophages.

\section{Ncf1 Alters Type 1 and 2 Responses in Lungs of AIPI}

To address the mechanism whereby Ncf1 regulated airway inflammation, we determined the cytokine profiles of lung tissue and serum. The mRNA expression of cytokines and chemokines in lung tissue was detected by RT-qPCR (Figures 4A, B), and their protein concentrations in serum were detected by Luminex assay (Figures $4 \mathrm{C}, \mathrm{D}$ ). The results showed that the mRNA expression of Ifng and Tnfa in lung tissue, and the protein concentrations of IFN- $\gamma$ and IL-12 in serum were increased in B10Q.Ncf1* mice, as compared with the wild-type mice, and their expression was decreased in $\mathrm{MN}$ mice (Figures 4B, D). In addition, the mRNA expression of Il10, Il33, and Vegf in lung was increased, whereas the protein concentration of IL-13 in serum was decreased, in Ncf1 


\section{A}

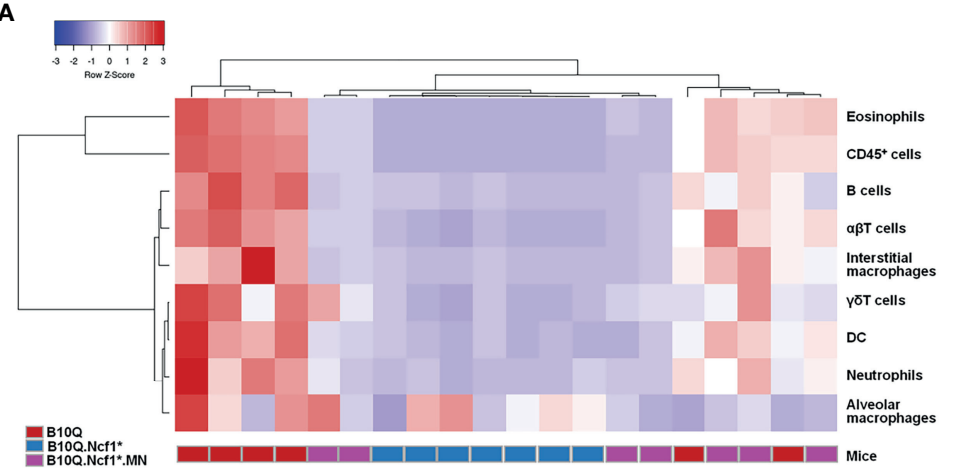

B

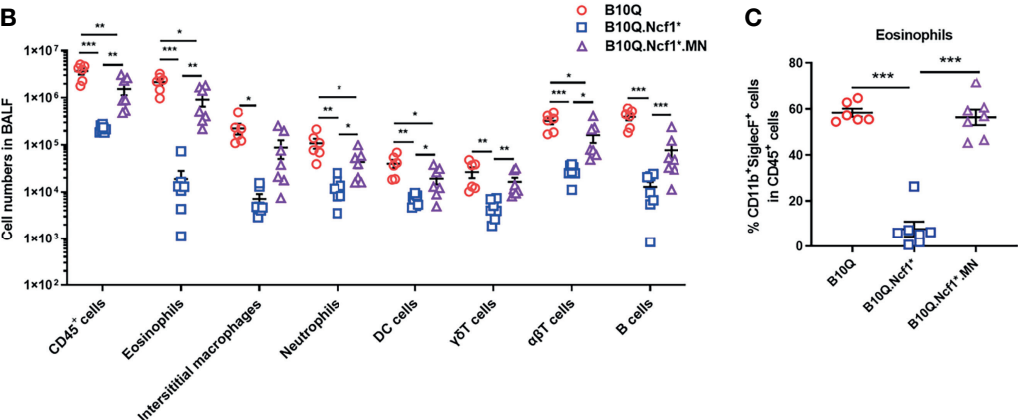

D
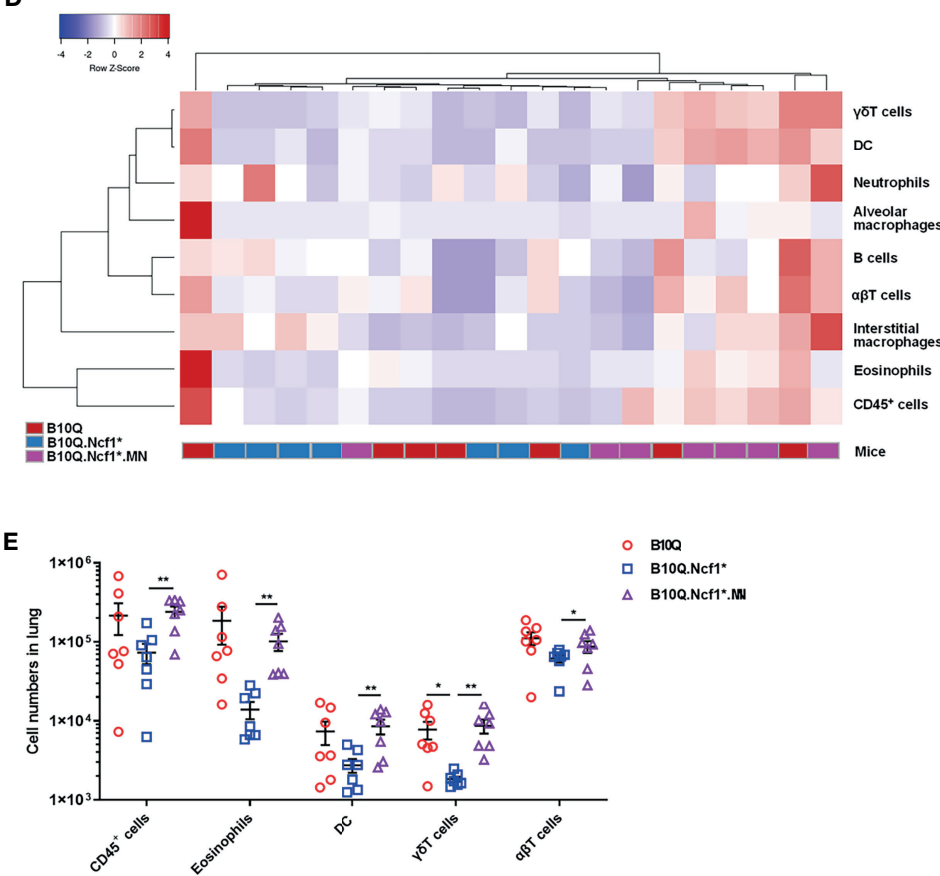

FIGURE 3 | Ncf1 deficiency reduces inflammatory infiltration in lung inflammation. (A, B) B10Q, B10Q.Ncf1* and B10Q.Ncf1*.MN mice were induced AIPI, the number of cells in BALF were detected by flow cytometry ( $n=6-7$ per group). Heat map with cell profile of each mouse, and the statistical analysis of cells with differences between groups are shown. (C) The proportion of eosinophils $\left(\mathrm{CD} 11 \mathrm{~b}^{+}\right.$SiglecF ${ }^{+}$cells) in $\mathrm{CD} 45^{+}$cells of BALF is shown in histogram. (D, E) Additionally, immune cells in lung tissues (upper left lobes) from the three strains were also detected by flow cytometry ( $n=7$ per group). Heat map with cell profile of each mouse, and the statistical analysis of cells with difference among groups are shown. All values are expressed as means \pm SEM. ${ }^{*} P<0.05$, ${ }^{\star \star} P<0.01$ and ${ }^{\star \star \star} P<$ 0.001 , using one-way ANOVA with post-hoc comparison (Fisher's) test. 


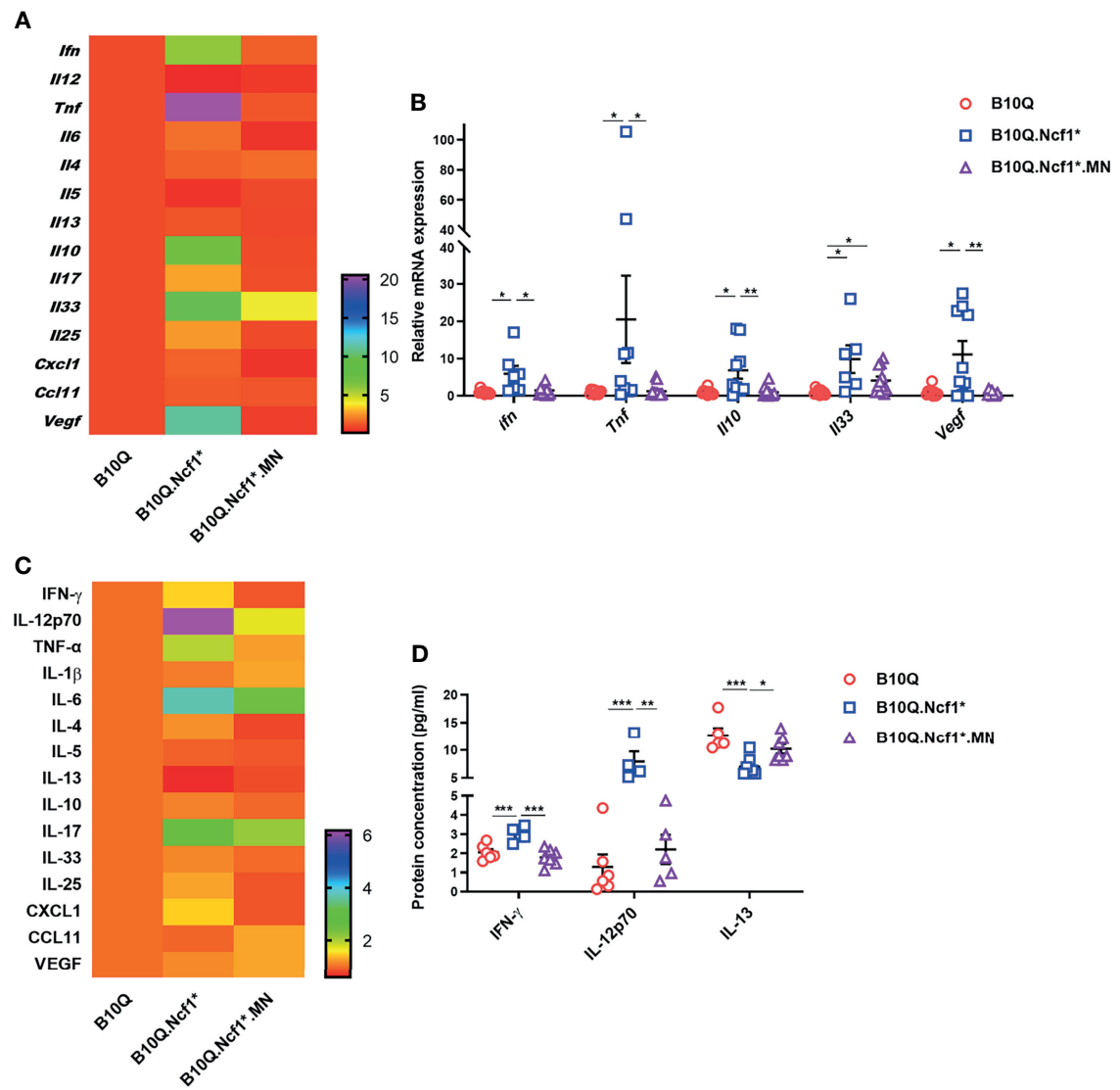

FIGURE 4 | Ncf1 alters type 1 and 2 responses in lungs of AIPI. (A, B) mRNA expression of cytokines and chemokines in lung tissues of AIPI mice were detected by RT-qPCR ( $n=6-12$ per group). (C, D) The protein concentration of various cytokines and chemokines in serum of three genotypes of mice were detected by Luminex assay ( $n=4-7$ per group). The heat maps $(\mathbf{A}, \mathbf{C})$ showed the mean values of gene/protein expression in each group of mice (B10.Q group is set as one in heat maps), and the statistically different gene/protein expression are shown in the histograms (B, D). All values are expressed as means \pm SEM. ${ }^{\star} P<0.05$, ${ }^{\star \star} P<$ 0.01 and ${ }^{\star \star *} P<0.001$, using one-way ANOVA with post-hoc comparison (Fisher's) test.

deficient mice, while $\mathrm{MN}$ reversed these changes to some extent (Figures 4B, D). Overall, Ncf1 deficiency was associated with an enhanced Th1-type of cytokine response, an effect that could be completely neutralized by expression of $N c f 1$ in macrophages. It raises the possibility that activation of the NOX2 complex in macrophages enable these cells to suppress a Th1 type of inflammatory response and thereby allowing a pathogenic Th2 type of reaction, explaining why expression of $N c f 1$ in macrophages promotes an allergic type of inflammation in AIPI.

\section{IL-33 Induced Lung Inflammation Is Regulated by Ncf1 Independent of Macrophages}

It was interesting to note that IL-33 and IL-25 expression was increased or showed an increased trend in $N c f 1$ deficient mice, suggesting that $N c f 1$ might regulate epithelial derived cytokines. These epithelial cytokines are believed to play important roles in mediating immune response in lung, and intranasal treatment of mice with IL-33 or IL-25, has been shown to induce pulmonary inflammation (25). To more directly test the role of these cytokines we treated the mice intranasally with IL-33 or IL-25 (Figure 5A), and the immune cell populations in lung tissues were analyzed by flow cytometry. In the IL-33 induced model, unlike the AIPI model, the heap map revealed a similarity of the inflammatory profiles between $N c f 1$ deficient mice and $\mathrm{MN}$ mice (Figure 5B). The numbers of the total immune cells, eosinophils, T cells, B cells, DC, $\gamma \delta \mathrm{T}$ cells and ILC2, were all decreased in the lungs of B10Q.Ncf1 $1^{\star}$ mice (Figure 5C). In particular, the proportions of eosinophils and ILC2 were decreased due to Ncf1 deficiency (Figure 5D). However, MN did not reverse the protective effect of $N c f 1$ deficiency, suggesting that $N c f 1$ was involved in this process through other types of cells.

On the contrary, $N c f 1$ appeared to play only a minor role in IL-25 stimulated lung inflammation. The total number of inflammatory cells, or the number of eosinophils and ILC2, as well as their proportion, did not change with Ncf1 deficiency, although macrophages, DC and $\gamma \delta \mathrm{T}$ cells were slightly downregulated (Figures S4A, B). Our results suggest that only the lung inflammatory response induced by IL-33, but not IL-25, is regulated by $N c f 1$. 
A

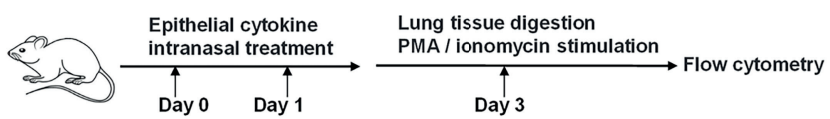

B
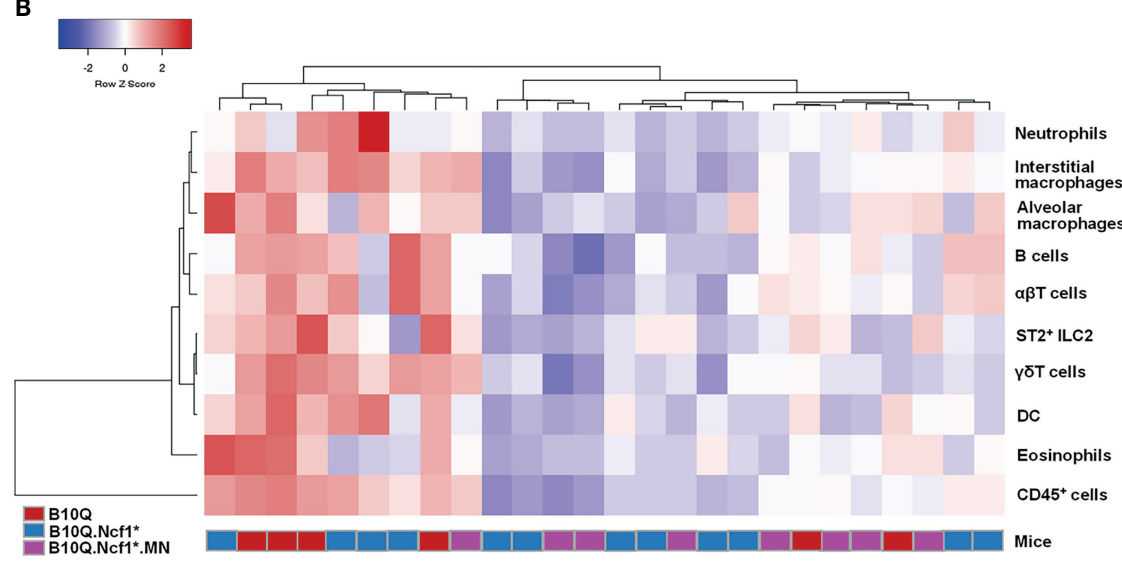

C

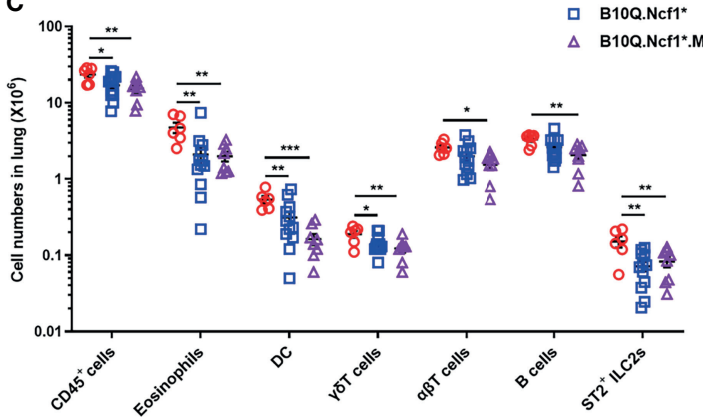

D

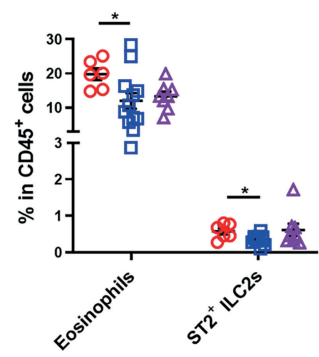

FIGURE 5 | IL-33 induced lung inflammation is regulated by Ncf1 independent on macrophages. (A) IL-33 was intranasally administered to mice to induce lung inflammation ( $n=6-12$ per group). (B, $\mathbf{C})$ The numbers of immune cells in the whole lung tissues were analyzed by flow cytometry, and heat map with cell profile of each mouse, and the statistical analysis of cells with difference among groups are shown. (D) The proportion of eosinophils (CD11 ${ }^{+}$SiglecF ${ }^{+}$cells) and ILC2 $\left(\mathrm{ST} 2^{+}\right.$Lineage $^{-}$cells) in $\mathrm{CD} 45^{+}$cells of lung are shown in histogram. All values are expressed as means \pm SEM. ${ }^{\star} P<0.05$, ${ }^{\star \star} P<0.01$ and ${ }^{\star \star \star} P<0.001$, using oneway ANOVA with post-hoc comparison (Fisher's) test.

\section{Ncf1 Deficiency Enhances Th1 Response and Inhibits ILC2 Activation in IL-33 Induced Lung Inflammation}

To explain how Ncf1 regulated IL-33 induced lung inflammation, we determined the cytokine production in this model. Since we found that $N c f 1$ deficiency could enhance Th1 response in the AIPI model, and $\alpha \beta$ T cells were also downregulated in the IL-33 induced model, we analyzed the IFN $-\gamma$ production in $\mathrm{CD}^{+} \mathrm{T}$ cells in the lungs by flow cytometry. The results showed that the proportion of IFN $-\gamma^{+}$cells in $\mathrm{CD}^{+} \mathrm{T}$ cells was increased in B10Q.Ncf1* mice compared with B10Q mice (Figures 6A, B). This result again underlined the importance of an enhanced Th1 response in the inflamed lungs regulated by $N c f 1$.

Next, we addressed whether ILC2 in the lung, known to be activated by IL-33, could be regulated by Ncf1. Therefore, the activation of ILC2 was evaluated through determining the IL-5 and IL-13 production. The results showed that the proportions of
IL $-5^{+}$and $\mathrm{IL}-13^{+}$cells within the ILC2 population, were decreased in B10Q.Ncf1 ${ }^{\star}$ mice as compared with their wildtype littermates, suggesting that $N c f 1$ deficiency deactivated ILC2, which could contribute to the disease protection (Figures 6C-E). Expression of $N c f 1$ in alveolar macrophages (i.e. in the $\mathrm{MN}$ mouse) did not influence the decreased number of $\mathrm{IL}^{+}$and IL13 ${ }^{+}$ILC2 lymphocytes (Figures 6C-E). Activation of ILC2 was also observed in the IL-25 induced model, but in this model no difference on cytokine production in $\mathrm{CD}^{+} \mathrm{T}$ cells and ILC2 could be observed (Figures S4C, D).

\section{IFN- $\gamma$ Induced Th1 Response Inhibits ILC2 Activation and Results in the Protective Effect of $\mathbf{N c f 1}$ Deficiency}

Since both Th1 enhancement and ILC2 deactivation were observed in Ncf1 deficient mice, to reveal the causality, we blocked the IFN- $\gamma$ activity in the IL-33 induced model. This 


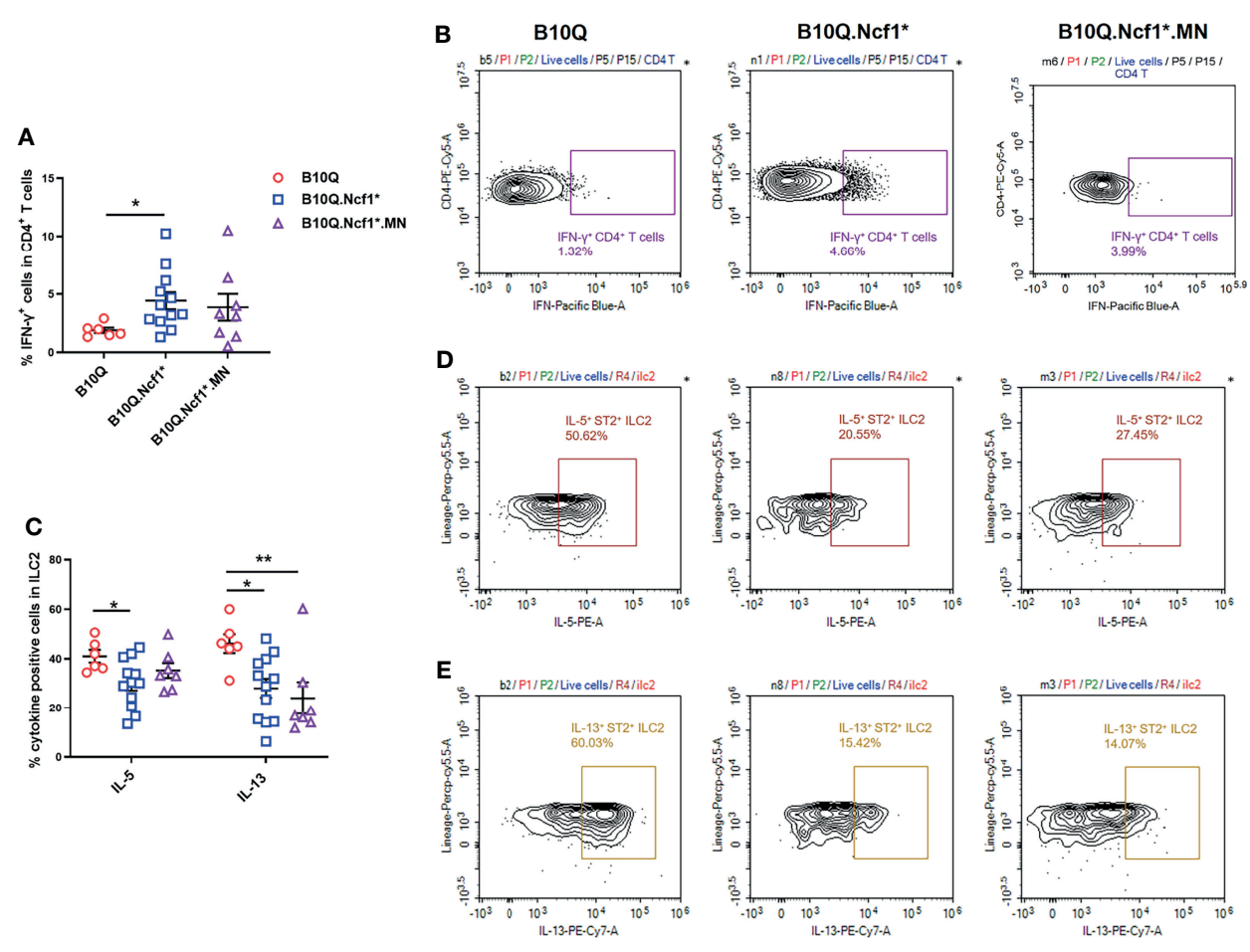

FIGURE 6 | Activation of Th1 cells and ILC2 is regulated by Ncf1 in lung inflammation induced by IL-33. The IFN- $\gamma$ positive cells in CD4 ${ }^{+}$T cells (A, B), and the IL-5 and IL-13 positive cells in ILC2 (C-E) were detected by flow cytometry in the whole lung tissues of mice treated with IL-33 ( $\mathrm{n}=6$-12 per group). The proportion of IFN- $\gamma$ positive cells in CD4 ${ }^{+} \mathrm{T}$ cells, and that of IL-5 and IL-13 positive cells in ILC2, were analyzed in histograms, and the representative plots are shown. All values are expressed as means \pm SEM. ${ }^{\star} P<0.05$ and ${ }^{\star \star} P<0.01$, using one-way ANOVA with post-hoc comparison (Fisher's) test.

was done by treating B10Q.Ncf1* mice with anti-IFN- $\gamma$ neutralizing antibodies (Figure 7A). Compared with isotype IgG group, mice treated with anti-IFN- $\gamma$ antibodies showed increased eosinophil numbers and proportion in the lungs, although there was no change of the ILC2 numbers (Figures $7 \mathbf{B}, \mathbf{C}$ ). The mice treated with anti-IFN- $\gamma$ antibodies showed an increased proportion of IL- $5^{+}$ILC2, and the proportion of IL- $13^{+}$cells in ILC2 also showed an increased trend, suggesting that blocking IFN- $\gamma$ pathway rescued the ILC2 activation (Figures 7D, E). Thus, our results indicate that Ncf1 deficiency enhances Th1 response, and thereby deactivates ILC2 lymphocytes, limiting the development of lung inflammation (Figure 8).

\section{DISCUSSION}

When phagocytic and antigen presenting cells are exposed to inflammatory stimuli, the Ncf1 protein is phosphorylated and together with other proteins forms the NOX2 complex in membranes, which is the critical oxidase mediating the oxidative burst $(26,27)$. A deficiency of the $N c f 1$ gene was first identified to be one of the genetic causative factors for development of chronic granulomatous disease (CGD) (28). Later naturally selected polymorphic alleles downsizing the ROS response, were detected, and found to be associated with several chronic autoimmune diseases in animal models and humans, such as SLE and RA $(12,14)$. However, the role of $N c f 1$ in allergic asthma remains unclear. We therefore tested the effect of a $N c f 1$ mutation, prohibiting a functional ROS response, using the classic antigen induced pulmonary inflammation, often used as a mouse model for human asthma. Our results indicate that a fully functional $N c f 1$ is needed to allow the induction of AIPI, since $N c f 1$ deficient mice showed a reduced immune cell infiltration in alveoli and airways. Moreover, by expressing $N c f 1$ in alveolar macrophages, the protective effect of $N c f 1$ deficiency was reversed.

The involvement of $N c f 1$ in inflammatory diseases in several studies suggests it to play a key role as an immune regulator. It was found that Ncf1 dependent NAPDH oxidase activity in macrophages was important for the induction of Tregs to control $\mathrm{T}$ cell-mediated inflammation (29), and Ncf1 is essential for Treg-mediated $\mathrm{CD}^{+}$effector $\mathrm{T}$ cell inhibition (30). Interestingly, these effects are mediated by ROS derived from the antigen presenting cells, which will oxidize the T cells in the vicinity, most likely during antigen presentation (31). Ncf1 was found to play an important role in virus induced hyperinflammatory lung injury via toll-like receptor (TLR) 4 pathway (18). In addition, mice lacking $N c f 1$ exhibited the reduced growth of implanted melanoma and lung carcinoma tumors, and the protection on the melanoma might be caused by increased Th1 cytokines but the reduced lung carcinoma might 
A
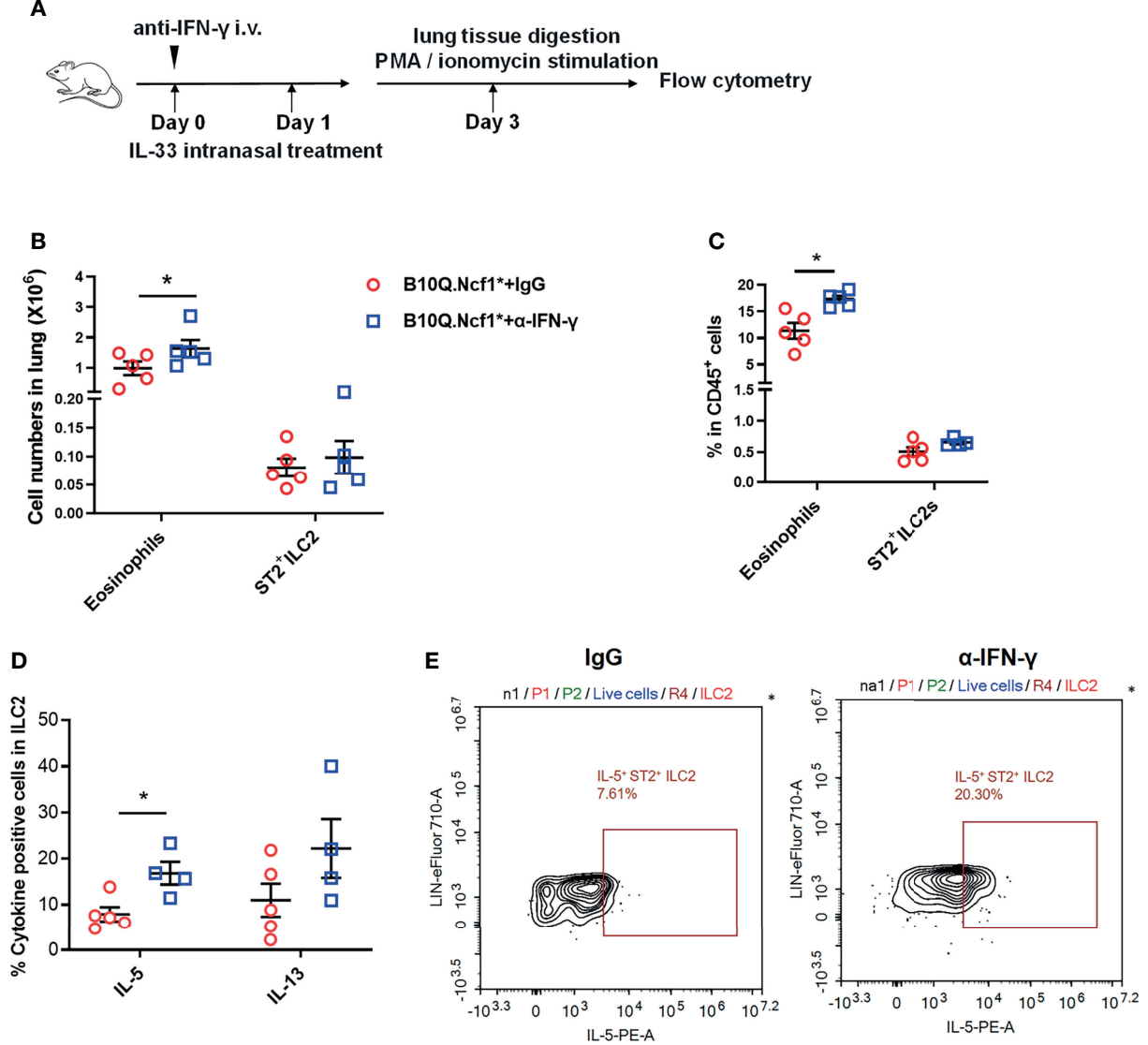

FIGURE 7 | Intervention of IFN- $\gamma$ rescues ILC2 activation and lung inflammation. (A) Anti-IFN- $\gamma$ neutralizing antibodies or isotype control antibodies were used for treatment of B10Q.Ncf1* mice in the IL-33 treated model ( $n=5$ per group). (B, C) The numbers of eosinophils and ILC2 in the whole lung tissue were analyzed by flow cytometry. The proportion of eosinophils and ILC2 in CD45 cells were determined in histogram. (D, E) In addition, the IL-5 and IL-13 positive cells within the ILC2 population were also detected by flow cytometry of cells from the whole lung tissues of the mice. The proportion of IL-5 and IL-13 positive cells in ILC2 were analyzed in histograms, and the representative plots of IL-5 are shown. All values are expressed as means \pm SEM. ${ }^{*} P<0.05$, using student's $t$ test.

be associated with increased Th2 cytokine production, suggesting the diverse immunoregulatory effects of $N c f 1$ in different disease conditions (15). In the present study, elevated levels of type 1 cytokines including IFN- $\gamma$ and IL-12 and decreased level of type 2 cytokine IL-13 in lung or serum of the AIPI model, suggested that allergic inflammation might be regulated by $N c f 1$ through reprogramming the type 1 and type 2 immune homeostasis, which is an important supplement to the immune regulation mechanism of $N c f 1$ in lung inflammation.

Recent studies have highlighted an important role of epithelial cytokines, including IL-25, IL-33 and TSLP, in lung inflammation. We found that the expression of IL-33 and IL-25 was increased in $N c f 1$ deficient mice, suggesting that they might be involved in the $N c f 1$-mediated regulation of pulmonary inflammation. IL-33, binding to its receptor ST2 on mast cells, Th2 cells, and ILC2, can directly induce airway inflammation and play an important role in the activation and differentiation of Th2 cells (32-34). IL-25 is rapidly released in the airway in response to allergenic stimuli, contributing to allergic inflammation, causing eosinophilia, inducing Th2-biased inflammation and excessive production of IL-4, IL-5 and IL-13 (35). Importantly, both IL-33 and IL-25 could activate ILC2, leading to production of IL-5 and IL-13, which mediates lung inflammation (25). Stimulation with either IL-33 or IL-25 in mice can induce lung inflammation, which are now widely used as models for studies of ILC2 regulation of lung inflammation $(36,37)$. An IL-33 connected response has been shown to mediate severe arthritis in mice with the Ncf1 mutation, provided that the immune response is directed towards Col2 in joint cartilage (38), which gave us some clues related to IL-33 and Ncf1. We therefore induced IL-33 and IL-25 treated mouse models using Ncf1 deficient mice. In line with the previous finding, $N c f 1$ deficiency reduced eosinophil infiltration, and increased IFN- $\gamma$ production in $\mathrm{CD}^{+} \mathrm{T}$ cells, re-emphasizing the importance of Th1 response enhancement in the inflammatory regulation of $N c f 1$. Besides, $N c f 1$ deficiency also inhibited the activation of ILC2, and decreased IL-5 and IL-13 production. However, supplementing macrophage Ncf1 could 


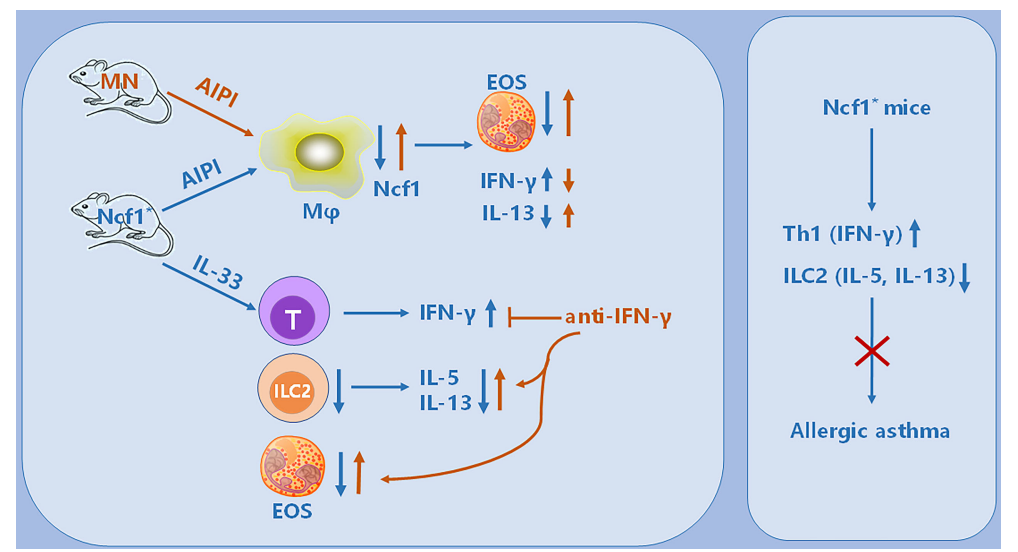

FIGURE 8 | Illustration of the immunoregulatory role of Ncf1 in pulmonary inflammation. In the OVA-induced AIPI model, Ncf1 deficient mice were protected from lung inflammation, with reduced eosinophil (EOS) infiltration, decreased IL-13 but increased IFN- $\gamma$ production. The MN mice, with alveolar macrophage-specific Ncf1 restoration, showed the reversed inflammation severity, suggesting a residential macrophage-dependent immunoregulatory effect of Ncf1 in the lung inflammation. In addition, Ncf1 deficient mice stimulated with IL-33 showed reduced eosinophilic inflammation in the lung, with decreased ILC2 activation and increased IFN- $\gamma$ production, while anti- IFN- $\gamma$ antibody treatment to mice reversed disease severity and increased ILC2 activation. Our results indicate that Ncf1 deficiency enhanced Th1 response and deactivate ILC2, to protect against lung inflammation in mice.

not reverse the above effects, suggesting a contributing effect by other cell types expressing $N c f 1$. In addition, it was found that the regulation and activation of ILC2 by IL-33, as compared with IL25 , might be different $(39,40)$. We also found that $N c f 1$ deficiency had limited effect on the IL-25 induced model, indicating that IL-33 but not IL-25 is more closely associated with the regulatory effect by $N c f 1$.

It is clearly of interest to reveal the causality of Th1 enhancement and ILC2 deactivation in the Ncf1 deficient context, which could be helpful for understanding the mechanism of the protective effect of $N c f 1$ deficiency. It has been reported that IFN- $\gamma$ production, induced through TLR9 activation, could alleviate ILC2-driven airway hyperresponsiveness (AHR) and airway inflammation (41). IFN- $\gamma$ could inhibit ILC2 expansion and IL-13 expression, thereby attenuating rhinovirus-induced mucous metaplasia (42). Thus, we thought that the antagonistic function of IFN- $\gamma$ on ILC2 activation could provide a clue to our question, leading us to an experiment to block IFN- $\gamma$. We applied anti-IFN- $\gamma$ antibody to IL-33 treated $N c f 1$ deficient mice, which rescued ILC2 activation and reversed the disease remission to some extent, suggesting that Ncf1 deficiency enhanced the Th1 response, thereby deactivating ILC2, to protect mice from lung inflammation.

It is interesting that the enhancement of the Th1 response due to Ncf1 deficiency contributes to regulate the type 2 allergic inflammation, since a stronger Th1 response seems to be closely related to the disease-promoting effect of $N c f 1$ in autoimmune diseases. The Th1 response, as well as the Th17 response, regulated by $N c f 1$ deficiency, may be important reasons for mice to be more susceptibility to autoimmune arthritis or lupus. NADPH oxidase deficiency could regulate Th lineage commitment to modulate autoimmunity, and superoxide provides a third signal for CD4 $\mathrm{T}$ cell effector responses (43, 44). ROS derived from the NOX2 complex on APCs, most likely hydrogen peroxide, can act as an immunological transmitter onto T cells and affect T cell signalling (31). However, the exact molecular mechanism remains unclear, which needs additional studies.

At present stage, our study has some limitations. We used OVA or epithelial cytokines to induce airway inflammation in this study. Although they all share many characteristics with asthma, house dust mite (HDM) induced model might be a better one to mimic the occurrence of human asthma from the induction mechanism. The role of Ncf1 in HDM animal model and human asthma will be our prior focus in the future. In addition, we now mainly focused on the regulatory effect of $N c f 1$ on lung inflammation from the aspects of histology and cytology. Due to the limitation of experimental conditions, we did not analyze the lung function, limiting us to fully understand the role of Ncf1 in asthma pathogenesis. However, the regulatory effect of Ncf1 on Th1 and Th2 in pulmonary inflammation should be convincing, and we also hope to further confirm the effect of $N c f 1$ on AHR in the future.

In conclusion, we confirm $N c f 1$ as an important immune regulator in pulmonary inflammation, orchestrating type 1 and 2 immune responses. This study is helpful for us to understand the pathogenesis of asthma and provides a potential target for human asthma. Ncf1 and its mediated oxidative stress may be a candidate intervention pathway in the treatment of pulmonary allergic inflammation.

\section{DATA AVAILABILITY STATEMENT}

The original contributions presented in the study are included in the article/Supplementary Material. Further inquiries can be directed to the corresponding authors. 


\section{ETHICS STATEMENT}

The animal study was reviewed and approved by the Institutional Animal Ethics Committee of Xi'an Jiaotong University.

\section{AUTHOR CONTRIBUTIONS}

All authors contributed to the discussion, writing, and revising of the manuscript. ML designed the study, performed the majority of the experiments, analyzed the data and wrote the manuscript. WZhang, $\mathrm{JZ}$, and XL performed experiments and analyzed data. FZ provided expert technical assistance. WZhu, LM, RH, and SL designed the research, analyzed the data, revised the manuscript, supervised and took the overall responsibility of the study. All authors contributed to the article and approved the submitted version.

\section{REFERENCES}

1. Kaur R, Chupp G. Phenotypes and Endotypes of Adult Asthma: Moving Toward Precision Medicine. J Allergy Clin Immunol (2019) 144(1):1-12. doi: 10.1016/j.jaci.2019.05.031

2. Tyler SR, Bunyavanich S. Leveraging -Omics for Asthma Endotyping. J Allergy Clin Immunol (2019) 144(1):13-23. doi: 10.1016/j.jaci.2019.05.015

3. Borish L. The Immunology of Asthma: Asthma Phenotypes and Their Implications for Personalized Treatment. Ann Allergy Asthma Immunol (2016) 117(2):108-14. doi: 10.1016/j.anai.2016.04.022

4. Kubo M. Innate and Adaptive Type 2 Immunity in Lung Allergic Inflammation. Immunol Rev (2017) 278(1):162-72. doi: 10.1111/imr.12557

5. Klein Wolterink RG, Kleinjan A, van Nimwegen M, Bergen I, de Bruijn M, Levani Y, et al. Pulmonary Innate Lymphoid Cells are Major Producers of IL5 and IL-13 in Murine Models of Allergic Asthma. Eur J Immunol (2012) 42 (5):1106-16. doi: 10.1002/eji.201142018

6. Lajoie S, Lewkowich IP, Suzuki Y, Clark JR, Sproles AA, Dienger K, et al. Complement-Mediated Regulation of the IL-17A Axis Is a Central Genetic Determinant of the Severity of Experimental Allergic Asthma. Nat Immunol (2010) 11(10):928-35. doi: 10.1038/ni.1926

7. Hall SL, Baker T, Lajoie S, Richgels PK, Yang Y, McAlees JW, et al. IL-17A Enhances IL-13 Activity by Enhancing IL-13-Induced Signal Transducer and Activator of Transcription 6 Activation. J Allergy Clin Immunol (2017) 139 (2):462-471 e414. doi: 10.1016/j.jaci.2016.04.037

8. Toskala E, Kennedy DW. Asthma Risk Factors. Int Forum Allergy Rhinol (2015) 5 Suppl 1:S11-6. doi: 10.1002/alr.21557

9. Backdahl L, Aoun M, Norin U, Holmdahl R. Identification of Clec4b as a Novel Regulator of Bystander Activation of Auto-Reactive T Cells and Autoimmune Disease. PloS Genet (2020) 16(6):e1008788. doi: 10.1371/journal.pgen.1008788

10. Zhu W, Lonnblom E, Forster M, Johannesson M, Tao P, Meng L, et al. Natural Polymorphism of Ym1 Regulates Pneumonitis Through Alternative Activation of Macrophages. Sci Adv (2020) 6(43):eaba9337. doi: 10.1126/ sciadv.aba9337

11. Fernandez Lahore G, Raposo B, Lagerquist M, Ohlsson C, Sabatier P, Xu B, et al. Vitamin D3 Receptor Polymorphisms Regulate T Cells and T Cell-Dependent Inflammatory Diseases. Proc Natl Acad Sci U S A (2020) 117(40):24986-97. doi: 10.1073/pnas.2001966117

12. Olofsson P, Holmberg J, Tordsson J, Lu S, Akerstrom B, Holmdahl R. Positional Identification of $\mathrm{Ncfl}$ as a Gene That Regulates Arthritis Severity in Rats. Nat Genet (2003) 33(1):25-32. doi: 10.1038/ng1058

13. Olsson LM, Nerstedt A, Lindqvist AK, Johansson SC, Medstrand P, Olofsson P, et al. Copy Number Variation of the Gene NCF1 Is Associated With Rheumatoid Arthritis. Antioxid Redox Signal (2012) 16(1):71-8. doi: 10.1089/ ars. 2011.4013

14. Olsson LM, Johansson AC, Gullstrand B, Jonsen A, Saevarsdottir S, Ronnblom L, et al. A Single Nucleotide Polymorphism in the NCF1 Gene Leading to Reduced Oxidative Burst Is Associated With Systemic Lupus

\section{FUNDING}

This work is supported by the National Natural Science Foundation of China (81970029, 82171724 and 82171784), the Shaanxi Province Natural Science Foundation (2020JQ082), and grants from the Swedish Strategic Science Foundation (SSF), the Knut and Alice Wallenberg Foundation, and the Swedish Research Council.

\section{SUPPLEMENTARY MATERIAL}

The Supplementary Material for this article can be found online at: https://www.frontiersin.org/articles/10.3389/fimmu.2021.783944/ full\#supplementary-material

Erythematosus. Ann Rheum Dis (2017) 76(9):1607-13. doi: 10.1136/ annrheumdis-2017-211287

15. Kelkka T, Pizzolla A, Laurila JP, Friman T, Gustafsson R, Kallberg E, et al. Mice Lacking NCF1 Exhibit Reduced Growth of Implanted Melanoma and Carcinoma Tumors. PloS One (2013) 8(12):e84148. doi: 10.1371/journal. pone.0084148

16. Chen B, Yang M, Li K, Li J, Xu L, Xu F, et al. Immune-Related Genes and Gene Sets for Predicting the Response to Anti-Programmed Death 1 Therapy in Patients With Primary or Metastatic Non-Small Cell Lung Cancer. Oncol Lett (2021) 22(1):540. doi: 10.3892/ol.2021.12801

17. Liu SY, Wang WZ, Yen CL, Tsai MY, Yang PW, Wang JY, et al. Leukocyte Nicotinamide Adenine Dinucleotide Phosphate-Reduced Oxidase Is Required for Isocyanate-Induced Lung Inflammation. J Allergy Clin Immunol (2011) 127(4):1014-23. doi: 10.1016/j.jaci.2010.12.008

18. Imai Y, Kuba K, Neely GG, Yaghubian-Malhami R, Perkmann T, van Loo G, et al. Identification of Oxidative Stress and Toll-Like Receptor 4 Signaling as a Key Pathway of Acute Lung Injury. Cell (2008) 133(2):235-49. doi: 10.1016/ j.cell.2008.02.043

19. Hultqvist M, Olofsson P, Holmberg J, Backstrom BT, Tordsson J, Holmdahl R. Enhanced Autoimmunity, Arthritis, and Encephalomyelitis in Mice With a Reduced Oxidative Burst Due to a Mutation in the Ncf1 Gene. Proc Natl Acad Sci U S A (2004) 101(34):12646-51. doi: 10.1073/pnas.0403831101

20. Sareila O, Jaakkola N, Olofsson P, Kelkka T, Holmdahl R. Identification of a Region in P47phox/NCF1 Crucial for Phagocytic NADPH Oxidase (NOX2) Activation. J Leukoc Biol (2013) 93(3):427-35. doi: 10.1189/jlb.1211588

21. Schuijs MJ, Png S, Richard AC, Tsyben A, Hamm G, Stockis J, et al. ILC2Driven Innate Immune Checkpoint Mechanism Antagonizes NK Cell Antimetastatic Function in the Lung. Nat Immunol (2020) 21(9):998-1009. doi: 10.1038/s41590-020-0745-y

22. Yao X, Wang W, Li Y, Lv Z, Guo R, Corrigan CJ, et al. Characteristics of IL-25 and Allergen-Induced Airway Fibrosis in a Murine Model of Asthma. Respirology (2015) 20(5):730-8. doi: 10.1111/resp.12546

23. Gelderman KA, Hultqvist M, Pizzolla A, Zhao M, Nandakumar KS, Mattsson R, et al. Macrophages Suppress T Cell Responses and Arthritis Development in Mice by Producing Reactive Oxygen Species. J Clin Invest (2007) 117 (10):3020-8. doi: 10.1172/JCI31935

24. Zhong J, Li Q, Luo H, Holmdahl R. Neutrophil-Derived Reactive Oxygen Species Promote Tumor Colonization. Commun Biol (2021) 4(1):865. doi: 10.1038/s42003-021-02376-8

25. Lambrecht BN, Hammad H, Fahy JV. The Cytokines of Asthma. Immunity (2019) 50(4):975-91. doi: 10.1016/j.immuni.2019.03.018

26. Chiriaco M, Salfa I, Di Matteo G, Rossi P, Finocchi A. Chronic Granulomatous Disease: Clinical, Molecular, and Therapeutic Aspects. Pediatr Allergy Immunol (2016) 27(3):242-53. doi: 10.1111/pai.12527

27. Holmdahl R, Sareila O, Olsson LM, Backdahl L, Wing K. Ncf1 Polymorphism Reveals Oxidative Regulation of Autoimmune Chronic Inflammation. Immunol Rev (2016) 269(1):228-47. doi: 10.1111/imr.12378 
28. Yu HH, Yang YH, Chiang BL. Chronic Granulomatous Disease: A Comprehensive Review. Clin Rev Allergy Immunol (2021) 61(2):101-13. doi: 10.1007/s12016-020-08800-x

29. Kraaij MD, Savage ND, van der Kooij SW, Koekkoek K, Wang J, van den Berg JM, et al. Induction of Regulatory T Cells by Macrophages Is Dependent on Production of Reactive Oxygen Species. Proc Natl Acad Sci U S A (2010) 107 (41):17686-91. doi: 10.1073/pnas.1012016107

30. Efimova O, Szankasi P, Kelley TW. Ncf1 (P47phox) Is Essential for Direct Regulatory T Cell Mediated Suppression of CD4+ Effector T Cells. PloS One (2011) 6(1):e16013. doi: 10.1371/journal.pone.0016013

31. Gelderman KA, Hultqvist M, Holmberg J, Olofsson P, Holmdahl R. T Cell Surface Redox Levels Determine T Cell Reactivity and Arthritis Susceptibility. Proc Natl Acad Sci U S A (2006) 103(34):12831-6. doi: 10.1073/pnas.0604571103

32. Yu QN, Guo YB, Li X, Li CL, Tan WP, Fan XL, et al. ILC2 Frequency and Activity are Inhibited by Glucocorticoid Treatment via STAT Pathway in Patients With Asthma. Allergy (2018) 73(9):1860-70. doi: 10.1111/all.13438

33. Schmitz J, Owyang A, Oldham E, Song Y, Murphy E, McClanahan TK, et al. IL-33, an Interleukin-1-Like Cytokine That Signals via the IL-1 ReceptorRelated Protein ST2 and Induces T Helper Type 2-Associated Cytokines. Immunity (2005) 23(5):479-90. doi: 10.1016/j.immuni.2005.09.015

34. Cherry WB, Yoon J, Bartemes KR, Iijima K, Kita H. A Novel IL-1 Family Cytokine, IL-33, Potently Activates Human Eosinophils. J Allergy Clin Immunol (2008) 121(6):1484-90. doi: 10.1016/j.jaci.2008.04.005

35. Xu M, Dong C. IL-25 in Allergic Inflammation. Immunol Rev (2017) 278 (1):185-91. doi: 10.1111/imr.12558

36. Wu YH, Lai AC, Chi PY, Thio CL, Chen WY, Tsai CH, et al. Pulmonary IL-33 Orchestrates Innate Immune Cells to Mediate Respiratory Syncytial VirusEvoked Airway Hyperreactivity and Eosinophilia. Allergy (2020) 75(4):81830. doi: 10.1111/all.14091

37. Yao X, Wang W, Li Y, Huang P, Zhang Q, Wang J, et al. IL-25 Induces Airways Angiogenesis and Expression of Multiple Angiogenic Factors in a Murine Asthma Model. Respir Res (2015) 16:39. doi: 10.1186/s12931-015-0197-3

38. Hagenow K, Gelderman KA, Hultqvist M, Merky P, Backlund J, Frey O, et al. Ncf1-Associated Reduced Oxidative Burst Promotes IL-33r+ T Cell-Mediated Adjuvant-Free Arthritis in Mice. J Immunol (2009) 183(2):874-81. doi: 10.4049/jimmunol.0900966

39. Salimi M, Barlow JL, Saunders SP, Xue L, Gutowska-Owsiak D, Wang X, et al. A Role for IL-25 and IL-33-Driven Type-2 Innate Lymphoid Cells in
Atopic Dermatitis. J Exp Med (2013) 210(13):2939-50. doi: 10.1084/ jem.20130351

40. Huang Y, Guo L, Qiu J, Chen X, Hu-Li J, Siebenlist U, et al. IL-25-Responsive, Lineage-Negative KLRG1(hi) Cells Are Multipotential 'Inflammatory' Type 2 Innate Lymphoid Cells. Nat Immunol (2015) 16(2):161-9. doi: 10.1038/ ni. 3078

41. Thio CL, Lai AC, Chi PY, Webster G, Chang YJ. Toll-Like Receptor 9Dependent Interferon Production Prevents Group 2 Innate Lymphoid CellDriven Airway Hyperreactivity. J Allergy Clin Immunol (2019) 144(3):682697 e689. doi: 10.1016/j.jaci.2019.03.008

42. Han M, Hong JY, Jaipalli S, Rajput C, Lei J, Hinde JL, et al. IFN-Gamma Blocks Development of an Asthma Phenotype in Rhinovirus-Infected Baby Mice by Inhibiting Type 2 Innate Lymphoid Cells. Am J Respir Cell Mol Biol (2017) 56(2):242-51.

43. Tse HM, Thayer TC, Steele C, Cuda CM, Morel L, Piganelli JD, et al. NADPH Oxidase Deficiency Regulates Th Lineage Commitment and Modulates Autoimmunity. J Immunol (2010) 185(9):5247-58. doi: 10.4049/jimmunol.1001472

44. Padgett LE, Tse HM. NADPH Oxidase-Derived Superoxide Provides a Third Signal for CD4 T Cell Effector Responses. J Immunol (2016) 197(5):1733-42. doi: 10.4049/jimmunol.1502581

Conflict of Interest: The authors declare that the research was conducted in the absence of any commercial or financial relationships that could be construed as a potential conflict of interest.

Publisher's Note: All claims expressed in this article are solely those of the authors and do not necessarily represent those of their affiliated organizations, or those of the publisher, the editors and the reviewers. Any product that may be evaluated in this article, or claim that may be made by its manufacturer, is not guaranteed or endorsed by the publisher.

Copyright (c) 2021 Li, Zhang, Zhang, Li, Zhang, Zhu, Meng, Holmdahl and Lu. This is an open-access article distributed under the terms of the Creative Commons Attribution License (CC BY). The use, distribution or reproduction in other forums is permitted, provided the original author(s) and the copyright owner(s) are credited and that the original publication in this journal is cited, in accordance with accepted academic practice. No use, distribution or reproduction is permitted which does not comply with these terms. 